Revista Educação e Políticas em Debate - v. 10, n. 1, p. 361-378, jan./abr. 2021 - ISSN 2238-8346

\title{
A oferta da educação básica em Roraima no contexto do Fundeb
}

The offer of basic education in Roraima in the context of Fundeb

L'offre d'éducation de base à Roraima dans le contexte du Fundeb

Maria Elcineide de Albuquerque Marialva ${ }^{1}$

Universidade Federal do Pará

Alcemir Pantoja Rodrigues ${ }^{2}$

Universidade Federal do Pará

Perla Sofia Andrade de Aquino ${ }^{3}$

Universidade Federal do Pará

Resumo: O estudo investiga o movimento das matrículas da educação básica estadual e municipal em Roraima a partir da implementação do Fundeb no período de 2009/2019, considerando a dinâmica de divisão de responsabilidades entre as redes de ensino na oferta educacional. A pesquisa é de cunho qualitativo e documental, a partir das fontes de dados: Sistema de Informações sobre Orçamentos Públicos em Educação (Siope) e o Instituto Nacional de Estudos e Pesquisas Educacionais Anísio Teixeira (Inep). As matrículas foram coletadas nas Sinopses Estatísticas da Educação Básica do Inep e no Laboratório de Dados Educacionais organizada por pesquisadores da Universidade Federal do Paraná (UFPR). Os dados financeiros foram coletados nos Relatórios Resumidos de Execução Orçamentária (RREO) estadual e municipal do Siope, no período de 2009 a 2019. Os resultados mostram redução das matrículas da educação básica na rede estadual de ensino e aumento destas na rede municipal, decorrente das transferências das matrículas da primeira para a segunda. No entanto, as etapas da educação básica apresentam um aumento positivo nas matrículas, isso se deve à inclusão destas na distribuição de recursos do Fundeb.

Palavras-chave: Matrículas. Educação Básica. Fundeb. Roraima.

Abstract: The study investigates the movement of the enrollment in public and municipal basic education in Roraima from the implementation of Fundeb in the period 2009/2019, taking into account the dynamics of the distribution of responsibilities between the educational networks in educational offer. The research is qualitative and documentary, based on data sources: Information System on Public Budgets for Education (Siope) and the National Institute of Educational Studies and Research Anísio Teixeira (Inep). Entries were

\footnotetext{
${ }_{1}^{1}$ Professora da Universidade Federal Rural da Amazônia. Doutoranda em Educação pelo Programa de PósGraduação em Educação da Universidade Federal do Pará. E-mail: elcineide@yahoo.com.br. Lattes: http://lattes.cnpq.br/7565126832554953. ORCID: https://orcid.org/o000-0002-5696-3418.

${ }^{2}$ Educação da Secretaria de Estado de Educação. Doutorando em Educação pelo Programa de Pós-Graduação em Educação da Universidade Federal do Pará. E-mail: alcemirp@gmail.com. Lattes: http://lattes.cnpq.br/9116827252137741 . ORCID: https://orcid.org/O000-0002-7253-1981.

${ }^{3}$ Mestranda em Educação pelo Programa de Pós-Graduação em Educação da Universidade Federal do Pará. Email: perlasofiaquino@gmail.com. Lattes: http://lattes.cnpq.br/5707384139659959. ORCID: https://orcid.org/0000-0002-9022-7326 .
} 
collected in the Inep Basic Education Statistics Summaries and in the Education Data Laboratory organized by researchers from the Federal University of Paraná (UFPR). The financial data was collected in the Summary Budget Execution Reports (RREO) of the State and the municipalities of Siope, in the period from 2009 to 2019. The results show a reduction in enrollment in basic education in the public educational system of education and increase of these in the municipal system, due to the transfer of enrollments from the first to the second. However, the basic education stages show a positive increase in enrollment, this is due to their inclusion in the distribution of Fundeb resources.

Keywords: Enrollment. Primary Education. Fundeb. Roraima.

Abstrait: L'étude examine le mouvement des inscriptions dans l'enseignement de base public et municipal à Roraima à partir de la mise en ouvre de Fundeb dans la période 2009/2019, en tenant compte de la dynamique de répartition des responsabilités entre les réseaux éducatifs dans l'offre éducative. La recherche est qualitative et documentaire, basée sur des sources de données: Système d'information sur les Budgets Publics de l'Éducation (SIOPE) et l'Institut National d'Études et de Recherche Éducatives Anísio Teixeira (INEP). Les inscriptions ont été collectées dans les synthèses des statistiques de l'éducation de Base de l'INEP et dans le Laboratoire de Données sur l'éducation organisé par des chercheurs de l'Université fédérale du Paraná (UFPR). Les données financières ont été collectées dans les Rapports Récapitulatifs d'Exécution du budget (RREO) de l'État et des municipalités du SIOPE, dans le période de 2009 à 2019. Les résultats montrent une réduction des inscriptions à l'éducation de base dans le système éducatif public d'enseignement et augmentation de celles-ci dans le système municipal, en raison de las transferts de las inscriptions de la premiére au seconde. Cependant, les étapes de l'éducation de base montrent une augmentation positive des inscriptions, ceci est dû à leur inclusion dans la distribution des ressources Fundeb.

Mots clés: Plaques d'immatriculation. Éducation de base. Fundeb. Roraima.

Recebido em: 1 de outubro de 2020 Aceito em: 4 de fevereiro de 2021

\section{Introdução}

Com a aprovação do Fundo de Manutenção e Desenvolvimento da Educação Básica e Valorização dos Profissionais da Educação (Fundeb - 2007 a 2020) pela Emenda Constitucional $n^{0} 53 / 2006$ e de sua regulamentação pela Lei $n^{\circ} 11.494 / 2007$, os recursos financeiros foram destinados a todas as etapas e modalidades da Educação Básica. É um fundo contábil que subvincula $20 \%$ da receita resultante de impostos dos estados e municípios à manutenção e desenvolvimento do ensino (Art. 212 da CF/88), excluindo apenas os impostos próprios municipais. Em seguida, tais recursos são redistribuídos proporcionalmente pelas matrículas ponderadas de cada rede de ensino pública. Essas matrículas correspondem à Educação Infantil (creche e pré-escola), sob competência 
Revista Educação e Políticas em Debate - v. 10, n. 1, p. 361-378, jan./abr. 2021 - ISSN 2238-8346 prioritária dos governos municipais, o Ensino Fundamental, compartilhado entre os governos estadual e municipal, o ensino médio sob responsabilidade dos estados (Art. 211 da $\mathrm{CF} / 1988$, alterado pela $\mathrm{EC} \mathrm{n}^{\circ}$ 14/1996).

Dessa forma, questiona-se se a implantação do Fundeb alterou a dinâmica de divisão de responsabilidade entre o governo estadual e o conjunto de municípios de Roraima em relação à oferta da educação básica. Roraima ocupa a posição mais setentrional da federação, ex-território; é área de fronteira com a República Bolivariana da Venezuela e com a Guiana; possui quinze municípios; apresenta um processo de ocupação populacional não indígena tardio; constituída pela forte presença dos movimentos migratórios de diversas regiões do país, com uma população de 631 mil habitantes em 2020, considerada a menor população do país. Todavia, possui o maior percentual de indígenas distribuído pelo Estado, sendo que a maior população indígena está localizada em Uiramutã (88,1\%), cidade ocupada por parte da terra indígena Raposa Serra do Sol, seguido do município de Normandia (56,9\%), Pacaraima (55,4\%) e Amajarí (55,8\%).

Em termos educacionais, o processo de implementação dos serviços com educação acompanha a trajetória histórica recente do Estado, com um crescimento regular no volume de escolas implantadas a partir dos anos de 1970. O atendimento educacional da população foi estruturado a partir do território federal, principalmente, por causa da busca pela terra, minérios, oportunidades de crescimento pessoal e profissional. Atualmente, de acordo com os dados do Censo escolar, existem 374 escolas e 75.386 alunos matriculados no Estado. Na área indígena são 254 escolas e 16.802 estudantes cursando as etapas de ensino da educação básica. Em relação aos alunos imigrantes venezuelanos, o Censo registrou 4.123 matrículas nas escolas da rede estadual em 2019. Soma-se a isso o valor-aluno-ano de Roraima, que em 2019 foi de $\mathrm{R} \$$ 5.239,65 (referência os anos iniciais do ensino fundamental urbano), sendo o maior em relação às demais unidades federativas e superior à média nacional, de $\mathrm{R} \$ 3.440,29$ no referido ano (Portaria Interministerial nº 3/2019).

Como parte da pesquisa de doutorado intitulada "Capacidade de atendimento de governos estaduais e municipais da Região Norte no financiamento dos sistemas de educação básica” surgiu o interesse em investigar o movimento das matrículas em Educação Básica da rede estadual e do conjunto dos municípios de Roraima a partir da implementação do Fundeb no período de 2009 a 2019, considerando a dinâmica de divisão de responsabilidade para oferta entre o Estado e os municípios. 
Revista Educação e Políticas em Debate - v. 10, n. 1, p. 361-378, jan./abr. 2021 - ISSN 2238-8346

Este estudo foi construído por meio de uma pesquisa de cunho qualitativo e documental, pois como destaca Kripka, Scheller e Bonotto (2015, p.57), esse tipo de pesquisa é primordial na medida em que o investigador mergulha "no campo de estudo procurando captar o fenômeno a partir das perspectivas contidas nos documentos, contribuindo com a área na qual ele se insere [...]”. As fontes de dados foram o Sistema de Informações sobre Orçamentos Públicos em Educação (Siope) e o Instituto Nacional de Estudos e Pesquisas Educacionais Anísio Teixeira (Inep). As matrículas foram coletadas nas Sinopses Estatísticas da Educação Básica do Inep e no Laboratório de Dados Educacionais, organizado por pesquisadores da Universidade Federal do Paraná (UFPR), no período de 2009 a 2019. A escolha desse período ocorreu devido à funcionalidade do Fundeb e por ser o que apresenta o maior volume de dados coletados referentes aos recursos financeiros do Fundo. Para visualização adequada das informações, as matrículas foram organizadas em tabelas e gráficos por dependência administrativa e por etapas e modalidades da Educação Básica. Os dados financeiros do Fundeb foram agrupados em tabelas na forma nominal.

O texto está organizado a partir dos seguintes itens: (1) breve apresentação do financiamento da educação básica pública a partir do Fundeb; (2) o Fundeb em Roraima; (3) a implementação do Fundeb nas matrículas da Educação Básica em Roraima; (4) aproximações conclusivas.

\section{Financiamento da Educação Básica pública com o Fundeb}

Os preceitos legais sobre o financiamento da educação básica no Brasil, fixados na Constituição Federal de 1988 (CF/88), tiveram importantes alterações a partir dos anos de 1990, principalmente com a adoção de fundos contábeis como mecanismos de redistribuição de recursos financeiros para a educação básica (MELCHIOR, 1997).

Encontra-se em vigência o Fundeb, instituído pela Emenda Constitucional $n^{\circ}$ 53/2006 e posteriormente regulamentado pela Lei $\mathrm{n}^{0} 11.494 / 2006$, tem como objetivo central a distribuição de recursos financeiros no âmbito de cada Estado para o financiamento de todas as etapas e modalidades da educação básica pública. Em outros termos, reúne vinte e sete fundos independentes, significando um fundo por Estado e Distrito Federal. É de natureza contábil, composto de impostos próprios e transferidos dos Estados e dos municípios, correspondente a subvinculação de $20 \%$. 
Revista Educação e Políticas em Debate - v. 10, n. 1, p. 361-378, jan./abr. 2021 - ISSN 2238-8346

O Fundeb redistribui uma parcela dos recursos arrecadados pela vinculação constitucional (Art. 212 da $\mathrm{CF} / 88$ ) com os Estados e Distrito Federal. Para tal redistribuição dos recursos do Fundo, adota-se como critério as matrículas da educação básica pública presencial, informadas pelo Censo Escolar do ano anterior. Com efeito, entre o governo estadual e seus municípios, os recursos são redistribuídos na proporção do número de alunos matriculados nas respectivas redes de ensino, ou seja, os governos municipais recebem recursos do Fundeb com base no número de alunos da educação infantil e do ensino fundamental e os Estados com base no total de alunos do ensino fundamental e médio. Assim como, a aplicação dos recursos deve ser direcionada a partir da responsabilidade constitucional que estabelece a atuação dos Estados e Municípios em relação à educação básica (FNDE, 2007).

Nos termos do art.10 da Lei $n^{\circ} 11.494 / 2007$, a distribuição proporcional dos recursos do Fundeb leva em consideração os fatores de ponderação ${ }^{4}$. Ao fixar essa ponderação, partese do fator base 1,0 atribuído aos anos iniciais do ensino fundamental urbano, de maneira que, as demais etapas e modalidades variam em torno de 0,7 (menor fator) e 1,30 (maior fator). Com isso, a aplicação dos fatores de ponderação gera valores por aluno/ano específicos para segmento da educação básica.

Além dos recursos subvinculados, há uma parcela de recursos federais que são assegurados sob título de complementação da União, que representa $10 \%$ do valor total da contribuição dos Estados e Municípios. Esse valor é repassado aos Estados que não conseguem atingir o valor por aluno/ano (VAA) mínimo definido nacionalmente, que "representa o mínimo per capita a ser assegurado no ano, de forma que os recursos da complementação da União sejam repassados aos estados que o valor aluno seja inferior ao mínimo” (BRASIL, 2008, p.15).

No caso de Roraima não são repassados valores de complementação do governo federal ao Fundo estadual, uma vez que, o valor aluno ano é sempre superior à média nacional. Pois, como explica Pinto e Alves (2011), os dados estimados em 2010 indicaram uma variação entre o valor mínimo Fundeb de $\mathrm{R} \$ 118 /$ mês, referentes aos estados de Alagoas e Maranhão até o máximo de $\mathrm{R} \$ 222 /$ mês do estado de Roraima. Por isso, o estado de Roraima deve ser observado com precaução, visto que a pequena e dispersa população não

\footnotetext{
${ }^{4}$ Os diferentes fatores de ponderação são definidos anualmente pela Comissão Intergovernamental de Financiamento para a Educação Básica de Qualidade.
} 
Revista Educação e Políticas em Debate - v. 10, n. 1, p. 361-378, jan./abr. 2021 - ISSN 2238-8346 indicam a capacidade real de investimento do referido estado. Assim, torna-se interessante observar a dinâmica do Fundeb e seu impacto nas matrículas da educação básica em Roraima.

\section{O Fundeb em Roraima}

Na composição dos recursos do Fundeb, parte da arrecadação de impostos são diretamente encaminhados ao Estado e seus respectivos municípios. Assim, esse fundo passa a ser considerado como o mais importante mecanismo da política de financiamento da educação básica no Brasil. Apesar desta proposta de redistribuição dos recursos financeiros, é a vinculação constitucional que garante o aporte dos recursos e estabelece as responsabilidades de cada esfera governamental no atendimento da educação básica.

Ao considerar a importância do Fundeb como mecanismo de financiamento da educação básica, apresenta-se no Gráfico 1 e na Tabela 3 (ver Apêndice A), os valores da movimentação dos recursos do fundo no âmbito do governo estadual e dos municípios de Roraima no período de 2009 a 2019, considerando a agregação dos recursos e a redistribuição entre os governos municipais.

Gráfico 1 - Roraima - movimentação financeira do Fundeb, segundo a contribuição e a receita do governo estadual e dos municípios - 2009 a 2019. Em milhões de $\mathrm{R} \$$

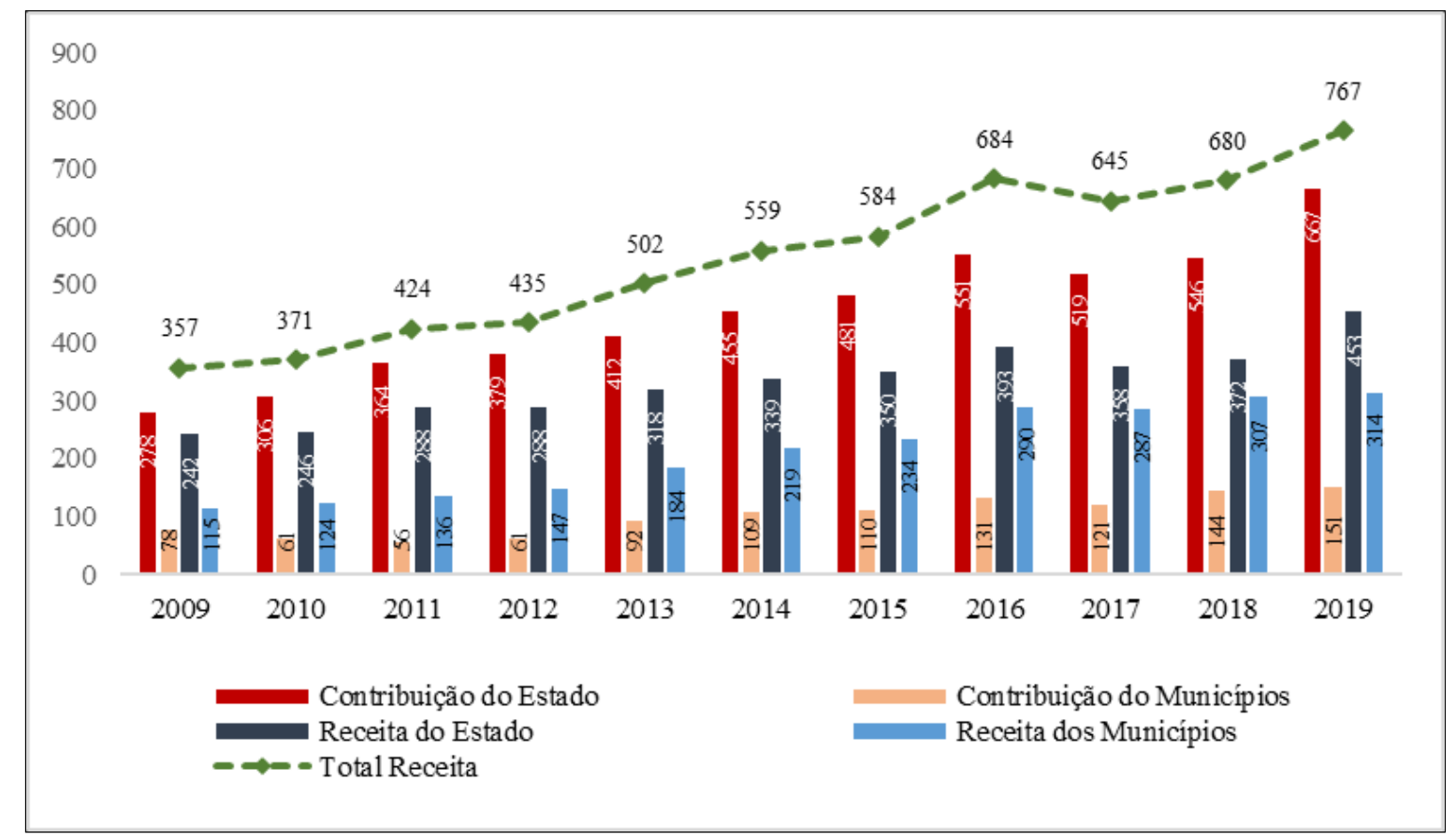

Fonte: SIOPE/FNDE 
Revista Educação e Políticas em Debate - v. 10, n. 1, p. 361-378, jan./abr. 2021 - ISSN 2238-8346

De acordo com dados do Gráfico 1, é notável que o Fundeb em Roraima agregou e redistribuiu, ao longo do período analisado, um volume crescente de recursos, que representa um montante que vai de $\mathrm{R} \$ 357$ milhões em 2009 para próximo de $\mathrm{R} \$ 767$ milhões em 2019 , uma diferença em torno de $117 \%$. Todavia, apesar do aumento expressivo dos investimentos do fundo, a lógica de distribuição dos recursos por meio das matrículas ponderadas da educação básica não necessariamente revela as prioridades educacionais de Roraima, pois além de apresentar o menor Produto Interno Bruto (PIB) do país, possui indicadores de qualidade de vida e desempenho escolar abaixo da média nacional, bem como, possui cerca de 23 mil alunos indígenas que são atendidos por aproximadamente dois mil professores em 339 escolas. Esses alunos indígenas correspondem a 16\% da rede escolar do Estado, ou seja, uma demanda que contabiliza para distribuição dos recursos do Fundeb, cujo coeficiente de ponderação correspondeu a 1,20 em 2020 (Agência Senado, 2020).

A contribuição financeira do governo estadual ao fundo manteve-se em torno de $78,5 \%$ do total arrecadado anualmente ao longo de todo o período, $\mathrm{R} \$ 278$ milhões em 2009 e $\mathrm{R} \$ 667$ milhões em 2019, enquanto a contribuição do conjunto dos municípios permaneceu em 22\%, $\mathrm{R} \$ 78$ milhões e $\mathrm{R} \$ 151$ milhões, respectivamente. Contudo, no período, os municípios foram gradualmente ampliando suas receitas, em maior proporção resultante da parcela da contribuição estadual. No primeiro ano, a receita do conjunto dos municípios foi bem superior ao valor da contribuição, de $\mathrm{R} \$ 115$ milhões, que representa $32,2 \%$ do fundo no Estado e no último ano foi de $\mathrm{R} \$ 314$ milhões, representando 40,9\% do total de receita do Fundeb em Roraima.

Em relação ao volume de recursos transferidos da rede estadual para os municípios por meio do Fundeb, isto é, a diferença entre a contribuição e a receita, nota-se que em 2009 foi de $\mathrm{R} \$ 36$ milhões e em 2019, de $\mathrm{R} \$ 214$ milhões, que corresponde a um crescimento em torno de $494 \%$. Salienta-se que essa receita corresponde à parte da contribuição não recuperada pelo governo estadual de Roraima, provavelmente decorrente das transferências de matrículas aos governos municipais. Por causa disso, o governo estadual perde parte de sua receita com as transferências aos seus municípios, o que gera ao conjunto de municípios um ganho positivo em relação ao valor da contribuição e o que retorna a eles, por exemplo, em 2019 o valor destinado ao fundo foi de $\mathrm{R} \$ 151$ milhões e o retorno foi de $\mathrm{R} \$ 314$ milhões, ou seja, um saldo positivo que equivale a $\mathrm{R} \$ 163$ milhões.

Esse fato permite algumas inferências, tais como: em 2009, quando completa a implementação do Fundeb e com o município sendo receptor de transferências do fundo estadual, 
Revista Educação e Políticas em Debate - v. 10, n. 1, p. 361-378, jan./abr. 2021 - ISSN 2238-8346 percebe-se que os municípios têm vantagem positiva em relação ao governo estadual, pois além de receberem os recursos do Fundeb ainda contam com os 25\% dos recursos próprios que não são destinados ao fundo e os $5 \%$ dos demais impostos que sobram quando retirados os $20 \%$ dos recursos resultantes de impostos que foram destinados ao Fundeb, conforme determinado na Lei 11. 949/2007. O aumento das receitas municipais, no período de 2009 a 2019, deve-se em grande parte às transferências dos recursos do fundo estadual, situação que deixa o estado de Roraima com menos recursos do Fundeb para financiar o sistema estadual de ensino.

\section{A contribuição do Fundeb para a oferta da educação básica em Roraima}

No sistema de ensino público do estado de Roraima as esferas estadual e municipal ofertam a Educação Básica, composta pelas etapas (educação infantil, ensino fundamental e médio) e as modalidades de ensino, conforme organização estabelecida constitucionalmente. Desse modo, a Tabela 1 reúne no período entre 2009 e 2019, as matrículas de educação básica organizadas por esfera administrativa, na qual é possível observar em maior proporção o atendimento da oferta sob responsabilidade do governo estadual, embora a partir de 2012 fica evidente a redução das matrículas na rede estadual de ensino e acréscimo da rede municipal, conforme pode ser visualizado na tabela 1.

Tabela 1 - Roraima - Matrícula da educação básica por esfera administrativa - 2009 - 2019.

\begin{tabular}{|c|c|c|c|c|c|c|c|c|}
\hline \multirow{3}{*}{ Anos } & \multicolumn{8}{|c|}{ Roraima } \\
\hline & \multicolumn{2}{|c|}{ Total } & \multicolumn{3}{|c|}{ Estadual } & \multicolumn{3}{|c|}{ Municipal } \\
\hline & Mat. (a) & $\% \Delta$ & Mat. (b) & $\% \Delta$ & $\%(b / a)$ & Mat. (c) & $\% \Delta$ & $\%(\mathbf{c} / \mathbf{a})$ \\
\hline 2009 & 133.887 & 100 & 82.058 & 100 & 61,3 & 41.148 & 100 & 30,7 \\
\hline 2010 & 141.348 & 5,6 & 86.148 & 5,0 & 60,9 & 43.838 & 6,5 & 31,0 \\
\hline 2011 & 144.200 & 7,7 & 84.722 & 3,2 & 58,8 & 46.276 & 12,5 & 32,1 \\
\hline 2012 & 144.548 & 8,0 & 81.464 & $-0,7$ & 56,4 & 49.638 & 20,6 & 34,3 \\
\hline 2013 & 145.949 & 9,0 & 76.561 & $-6,7$ & 52,5 & 54.251 & 31,8 & 37,2 \\
\hline 2014 & 149.079 & 11,3 & 74.685 & $-9,0$ & 50,1 & 56.113 & 36,4 & 37,6 \\
\hline 2015 & 149.058 & 11,3 & 73.068 & $-11,0$ & 49,0 & 56.716 & 37,8 & 38,0 \\
\hline 2016 & 150.049 & 12,1 & 70.433 & $-14,2$ & 46,9 & 60.385 & 46,8 & 40,2 \\
\hline 2017 & 155.362 & 16,0 & 72.311 & $-11,9$ & 46,5 & 63.666 & 54,7 & 41,0 \\
\hline 2018 & 156.855 & 17,2 & 73.308 & $-10,7$ & 46,7 & 65.357 & 58,8 & 41,7 \\
\hline 2019 & 166.147 & 24,1 & 76.073 & $-7,3$ & 45,8 & 71.534 & 73,8 & 43,1 \\
\hline
\end{tabular}

Fonte: Laboratório dos Dados Educacionais - UFPR

Ao analisar os dados da tabela 1, observa-se que mais da metade das matrículas da educação básica estão sob responsabilidade da rede estadual de ensino, em média 52,3\% do total 
Revista Educação e Políticas em Debate - v. 10, n. 1, p. 361-378, jan./abr. 2021 - ISSN 2238-8346 das matrículas do Estado de Roraima no período de 2009 a 2019, ou seja, as matrículas no respectivo estado permanecem em maior parte estadualizada, apesar de visível a queda no movimento dessas matrículas e a crescente circulação na esfera municipal nos respectivos anos em análise, que correspondem aos anos de execução do Fundeb.

Salienta-se que com o Fundeb a perda das matrículas da rede estadual ocorre por causa das transferências destas para os municípios. Isso fica evidente quando se compara os percentuais por ano, pois, em 2009 a rede estadual respondia por cerca de $61,3 \%$ das matrículas e em 2019 eram apenas 45,8\% do total, que representa uma perda de 7,3\% da matrícula desse nível de ensino. Sonobe et. al. (2018) sinalizam preocupação com relação a esse fato, pois ocorre em um momento que se deveria ampliar o atendimento nas redes estaduais às demandas da educação básica definidas na EC 59/2009 e mais recentemente pelas metas do Plano Nacional de Educação - PNE 2014-2024.

De modo inverso, em 2009 a rede municipal de ensino atendia o equivalente a 30,7\%, enquanto em 2019 atingiu 43,1\% do total de matrículas da educação básica em Roraima. O que sugere que não houve municipalização na educação básica no período, apenas um maior crescimento das matrículas na rede municipal de ensino (SALES; SILVA, 2013).

Em resumo, as redes municipais vêm assumindo as matrículas da educação básica ao longo do período analisado, apesar da rede estadual apresentar um número maior de alunos matriculados em Roraima.

Na sequência são analisadas as matrículas da Educação Básica por etapa de ensino, com o intuito de identificar o movimento de cada uma, conforme pode ser observado na tabela 2.

Tabela 2 - Roraima - Matrícula da educação básica por etapa de ensino - 2009 - 2019

\begin{tabular}{|c|c|c|c|c|c|c|c|c|c|c|c|}
\hline \multirow{3}{*}{ Anos } & \multicolumn{11}{|c|}{ Roraima } \\
\hline & \multicolumn{2}{|c|}{ Total } & \multicolumn{3}{|c|}{ Educação Infantil } & \multicolumn{3}{|c|}{ Ensino Fundamental } & \multicolumn{3}{|c|}{ Ensino Médio } \\
\hline & Mat. (a) & $\% \Delta$ & Mat. (b) & $\% \Delta$ & $\%(\mathbf{b} / \mathbf{a})$ & Mat. (c) & $\% \Delta$ & $\%$ (c/a) & Mat. (d) & $\% \Delta$ & $\%(d / a)$ \\
\hline 2009 & 133.887 & 100 & 17.170 & 100 & 12,8 & 86.547 & 100 & 64,6 & 17.512 & 100 & 13,1 \\
\hline 2010 & 141.348 & 5,6 & 16.847 & $-1,9$ & 11,9 & 91.556 & 5,8 & 64,8 & 18.463 & 5,4 & 13,1 \\
\hline 2011 & 144.200 & 7,7 & 18.293 & 6,5 & 12,7 & 93.607 & 8,2 & 64,9 & 19.757 & 12,8 & 13,7 \\
\hline 2012 & 144.548 & 8,0 & 18.980 & 10,5 & 13,1 & 92.564 & 7,0 & 64,0 & 21.055 & 20,2 & 14,6 \\
\hline 2013 & 145.949 & 9,0 & 17.465 & 1,7 & 12,0 & 95.158 & 9,9 & 65,2 & 21.916 & 25,1 & 15,0 \\
\hline 2014 & 149.079 & 11,3 & 21.630 & 26,0 & 14,5 & 92.795 & 7,2 & 62,2 & 22.721 & 29,7 & 15,2 \\
\hline 2015 & 149.058 & 11,3 & 21.551 & 25,5 & 14,5 & 91.651 & 5,9 & 61,5 & 22.995 & 31,3 & 15,4 \\
\hline 2016 & 150.049 & 12,1 & 23.004 & 34,0 & 15,3 & 92.618 & 7,0 & 61,7 & 22.461 & 28,3 & 15,0 \\
\hline 2017 & 155.362 & 16,0 & 24.904 & 45,0 & 16,0 & 93.652 & 8,2 & 60,3 & 22.838 & 30,4 & 14,7 \\
\hline 2018 & 156.855 & 17,2 & 26.767 & 55,9 & 17,1 & 96.582 & 11,6 & 61,6 & 22.191 & 26,7 & 14,1 \\
\hline 2019 & 166.147 & 24,1 & 28.064 & 63,4 & 16,9 & 102.264 & 18,2 & 61,6 & 23.587 & 34,7 & 14,2 \\
\hline
\end{tabular}

Fonte: Laboratório de Dados Educacionais - UFPR. 
Revista Educação e Políticas em Debate - v. 10, n. 1, p. 361-378, jan./abr. 2021 - ISSN 2238-8346

Em relação ao total de matrículas da educação básica, nota-se que há aumento de 24,1\%, ou seja, percebe-se a evolução positiva das matrículas nesse nível de ensino em Roraima, no período analisado. Além disso, todas as etapas de ensino da educação básica apresentaram crescimento em termos da oferta no estado. Esse fato contribui para elevar os recursos financeiros por meio da distribuição dos recursos do Fundeb em cada esfera governamental, uma vez que para tal repartição dos recursos, adota-se como critério o quantitativo de matrículas ponderadas por rede de ensino, de acordo com Gomes (2014), a rede estadual exclusivamente oferta ensino fundamental e ensino médio e a rede municipal atua prioritariamente no ensino fundamental e na educação infantil.

Os dados da tabela 2 indicam que as matrículas da educação infantil apresentaram crescimento expressivo de 63,4\% no período em análise. Acredita-se que isso decorre da inclusão dessa etapa de ensino no critério de redistribuição dos recursos do Fundeb, uma vez que estimulou o atendimento à educação infantil, em creches e pré-escolas em Roraima, passando a redistribuir recursos aos municípios em função das matrículas registradas.

No entanto, considera-se que os recursos do Fundeb ainda são insuficientes quando se trata do atendimento à demanda da Educação no estado de Roraima, apesar de serem necessários, pois não há existência de novos recursos com este fundo, visto que apenas redistribui os recursos financeiros já existentes da vinculação constitucional. Além disso, para a redistribuição dos recursos do Fundeb são adotados coeficientes de ponderação, que de certo modo, são considerados baixos por não representarem as despesas reais com a educação básica. Para Pinto (2007), esses baixos fatores de ponderação inviabilizam a ampliação do atendimento nas redes municipais de educação infantil, assim como, a garantia de qualidade. Além de não ter relação com o custo real de cada segmento, proporciona a permanência do baixo custo na educação infantil e a focalização dos recursos no ensino fundamental.

Nessa perspectiva, Arelaro (2008) já chamava atenção para as condições de financiamento da educação básica previstas na Lei 11.494/2007 que regulamentou o Fundeb, uma vez que, o coeficiente de valorização, por exemplo, de creches e pré-escolas foi estabelecido abaixo do valor dos anos iniciais do ensino fundamental urbano, o que gerou e que ainda gera uma diferença significativa no valor por aluno, considerando que os custos da educação infantil são os mais altos, não podendo sequer ser equiparados aos do ensino fundamental.

No que se refere ao Ensino Fundamental, constata-se que o quantitativo de matrículas apresentou um acréscimo de 18,2\% entre 2009 a 2019. Em termos percentuais é a etapa com maior número de matrículas em Roraima, atingindo em média 62,9\% do 
Revista Educação e Políticas em Debate - v. 10, n. 1, p. 361-378, jan./abr. 2021 - ISSN 2238-8346 atendimento em relação às demais etapas de ensino da educação básica. No entanto, os dados revelam que no estado de Roraima ainda falta atingir a Meta 2 do PNE (2014-2024), que seria a universalização do ensino fundamental em 95\% do atendimento da população de 06 a 14 anos de idade até o final de vigência do plano, que será em 2024.

Em relação ao ensino médio, observa-se crescimento no número de matrículas de $34,7 \%$ no período analisado. O atendimento das matrículas dessa etapa de ensino em Roraima atingiu 14,4\%, no período de 2009 a 2019.

Nota-se a partir dados da tabela 2, que no estado de Roraima, apesar do acrescimento das matrículas em todas as etapas de ensino da educação básica, o Fundeb contribuiu pouco para expansão da oferta da educação infantil e do ensino médio, todavia, consolida uma situação de oferta ainda muito centralizada no ensino fundamental em detrimento dos demais segmentos da educação básica.

Em seguida, apresenta-se as matrículas da educação infantil por atendimento na rede estadual e rede municipal de ensino no período de 2009 a 2019, considerando a constituição da educação infantil pelos subsegmentos creche e pré-escola, conforme Gráfico 2.

Gráfico 2 - Roraima - Matrículas da Educação Infantil - Estado e municípios - 2009 a 2019.

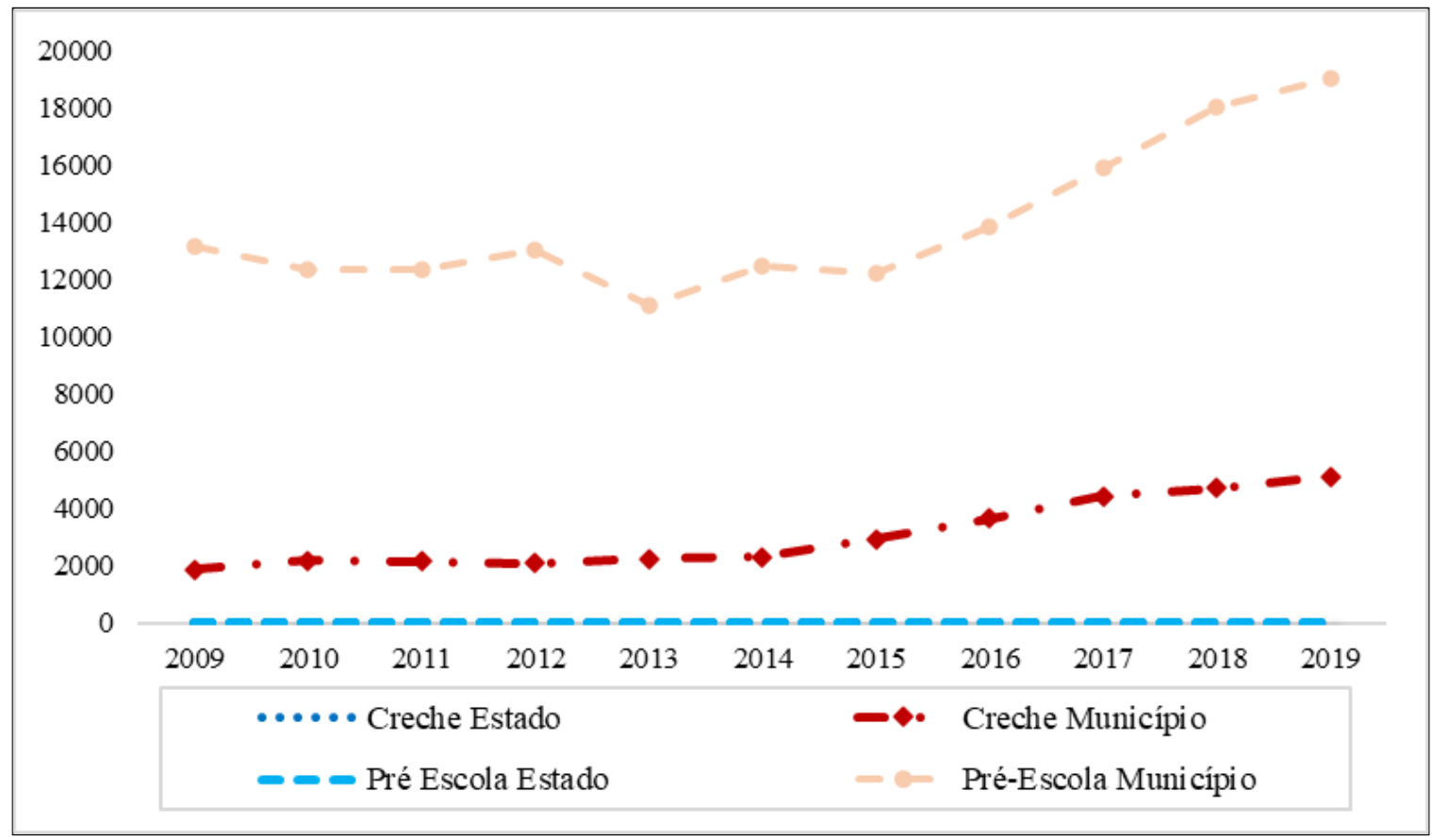

Fonte: Laboratório de Dados Educacionais - UFPR

No gráfico 2 é possível observar que as redes municipais são as principais responsáveis pela oferta da Educação Infantil, diferentemente da rede estadual que não 
Revista Educação e Políticas em Debate - v. 10, n. 1, p. 361-378, jan./abr. 2021 - ISSN 2238-8346 apresenta nenhuma matrícula de Creche e pré-escola em Roraima. Isso se justifica mediante a Emenda Constitucional (EC) no 14/1996, que altera o artigo 211 da CF/88, ao tratar sobre a organização do ensino e a divisão de responsabilidades entre as instâncias governamentais quando define que os municípios atuarão prioritariamente no ensino fundamental e na educação infantil e os estados, no ensino fundamental e médio ( $\$ 2^{\circ}$ e $3^{\circ}$ da EC 14/1996). Essa determinação legal vem sendo praticada pelos municípios, em interseção com a política educacional do governo federal.

A participação municipal na oferta da Educação Infantil passou de 15 mil em 2009 para aproximadamente 24 mil estudantes matriculados na rede municipal de ensino de Roraima em 2019, ou seja, uma evolução de 60,6\% das matrículas das crianças de 0 a 5 anos de idade. Santos e Souza Jr (2017) afirmam que apesar do crescimento no atendimento da Educação Infantil, ainda é muito inferior a demanda por vaga, implicando em desafios para além da ampliação de vaga, mas por projetos de melhoria à infraestrutura e a qualidade das instituições de educação infantil, habilitações especificas aos docentes em creches e préescolas, assim como, elevação dos investimentos de recursos públicos para atender as condições necessárias para este segmento.

As matrículas da educação infantil creche municipal registram crescimento da ordem de $172 \%$ nesse período do Fundeb, ao passo que as matrículas da pré-escola cresceram em apenas $44,6 \%$ no período analisado. De todo modo, evidencia-se a evolução positiva ao longo do período, embora seja evidente que a cobertura educacional da creche ainda está muito longe de atender a demanda, uma vez que, na média a oferta foi de apenas $17,6 \%$, enquanto o atendimento da pré-escola foi em média $82,4 \%$.

Esse movimento das matrículas reflete diretamente no valor por aluno repassado pelo Fundeb tanto da creche quanto da pré-escola. Em 2019, esses valores foram de $\mathrm{R} \$$ 6.025,59 para creche parcial e $\mathrm{R} \$ 5.501,63$ para pré-escola parcial. Valores estes acima da média nacional, que foi de $\mathrm{R} \$ 3.238,52 \mathrm{em} 2019$. Acredita-se que os valores por aluno ano de Roraima são superiores à média nacional por causa do baixo número de estudantes matriculados nessa etapa de ensino, o que acarreta um esforço do poder público municipal no atendimento à educação infantil, sob sua responsabilidade.

No Gráfico 3, apresenta-se a movimentação das matrículas do ensino fundamental anos iniciais e finais nas redes estadual e municipal de ensino de Roraima no período de 2009 a 2019. 
Gráfico 3 - Roraima - Matrículas do Ensino Fundamental - Estado e municípios - 2009 a 2019.

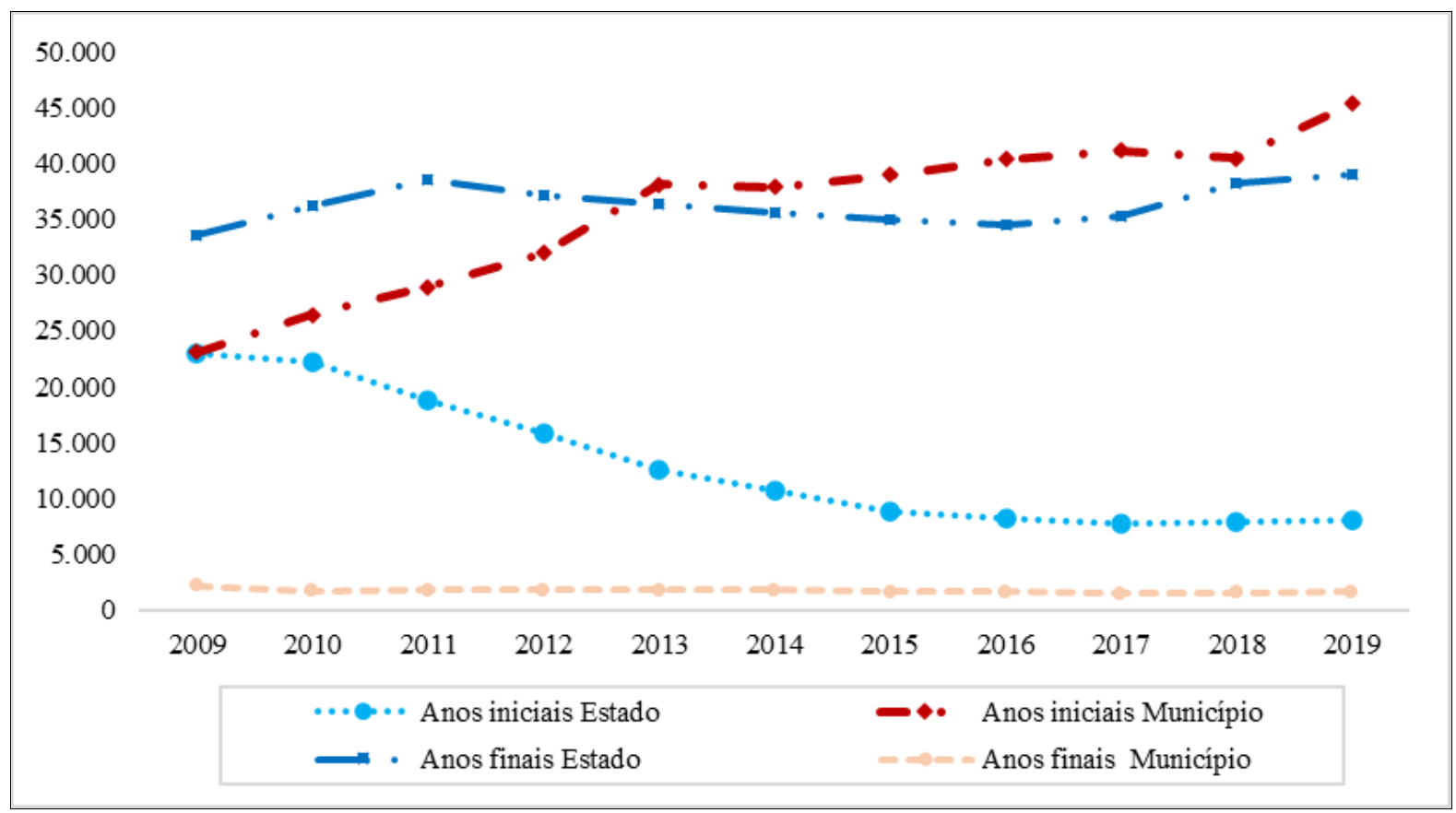

Fonte: Laboratório de Dados Educacionais - UFPR

Do total de matrículas do ensino fundamental, percebe-se que em 2019 tanto a oferta da rede estadual quanto a rede municipal atingiram $50 \%$ da oferta no Estado, isto é, 47.075 mil matrículas estaduais e 46.982 matrículas nas redes municipais de ensino.

Os dados do Gráfico 3 indicam que apesar da inserção das crianças de seis anos no ensino fundamental para nove anos (EC 59/2009) reverteu a queda do número de matrículas nos anos iniciais dessa etapa na rede estadual de ensino, de 61,5\%, todavia, há um aumento expressivo da oferta municipal de 96,2\% entre os anos de 2009 a 2019. Assim sendo, pode-se afirmar que, no referido período, o crescimento das matrículas da rede municipal, antes mesmo da vigência do Fundef, pode ser entendido como uma corrida antecipada dos municípios, por matrícula, com vistas a aumentar suas receitas. Dito de outro modo, “[ $\ldots$.$] as redes municipais se anteciparam no incremento de$ matrículas de modo a se precaverem quanto aos impactos sobre suas receitas" (BASSI; FERMINO, 2011 , p. 16)

Nesse contexto, pode-se afirmar que em Roraima houve maior participação da rede municipal na oferta dos anos iniciais do Ensino Fundamental no período de 2009 a 2019. Em contrapartida, há maior participação da rede estadual no atendimento dos anos finais do ensino fundamental em Roraima no período analisado. 
Revista Educação e Políticas em Debate - v. 10, n. 1, p. 361-378, jan./abr. 2021 - ISSN 2238-8346

O Gráfico 4 apresenta as matrículas do ensino médio por rede de ensino estadual e municipal nos anos de 2009 a 2019.

Gráfico 4 - Roraima - Matrículas do Ensino Médio - Estado e municípios - 2009 a 2019.

25.000

20.000

15.000

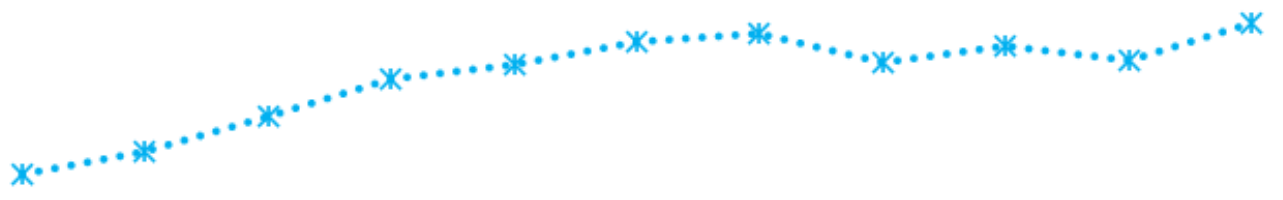

10.000

5.000

0

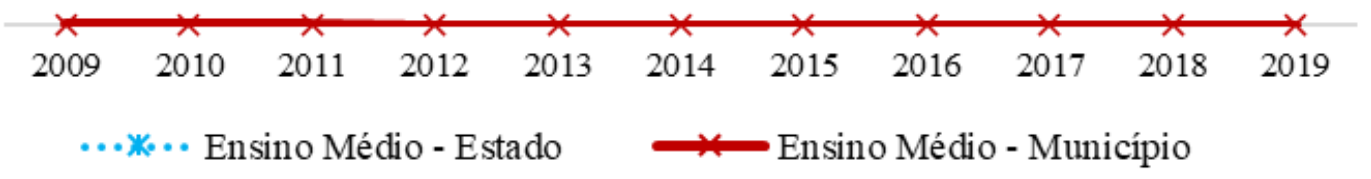

Fonte: Sinopses Estatísticas da Educação Básica - INEP.

Observa-se a partir dos dados do Gráfico 4 que a rede estadual, majoritariamente, atende as matrículas do ensino médio em Roraima. Além disso, constata-se acréscimo nas matrículas dessa rede de ensino em 35,6\% no período em análise. Destaca-se, neste caso, a estadualização das matrículas do ensino médio no estado, ou seja, maior participação da oferta pública estadual, não apenas em Roraima, mas com uma tendência nacional.

Em linhas gerais, constata-se como tendências na oferta da educação básica com o Fundeb em Roraima, a maior participação da rede municipal de ensino nas matrículas da Educação Infantil e anos iniciais do ensino fundamental e maior participação da rede estadual de ensino nas matrículas dos anos finais do ensino fundamental e oferta estadualizada do ensino médio. Esse cenário evidencia a repartição de responsabilidade entre o estado de Roraima e seus municípios no quesito da educação básica, conforme as orientações do ordenamento constitucional legal em relação a esta matéria. 
Revista Educação e Políticas em Debate - v. 10, n. 1, p. 361-378, jan./abr. 2021 - ISSN 2238-8346

\section{Aproximações conclusivas}

Em Roraima, a implementação do Fundeb se mostrou de modo positivo para o conjunto de municípios a partir das transferências de recursos do Estado. Em contrapartida, tais transferências geraram perda de receita ao próprio governo estadual.

Além disso, a implementação deste Fundo alterou a dinâmica de divisão de responsabilidades entre o governo estadual e o conjunto de municípios em Roraima, em termos, da oferta da educação básica, que apesar da rede estadual apresentar redução das matrículas a partir de 2012 e acréscimo de matrículas da rede municipal ao longo do período, atingindo 50\% das matrículas em 2019, ainda, percebe-se uma oferta estadualizada das matrícula da educação básica em Roraima, ou seja, há maior participação da rede estadual no atendimento desse nível de ensino ao longo do período estudado.

De modo geral, as alterações legais nas regras constitucionais sobre o financiamento da educação que reorientaram a trajetória dos recursos financeiros vinculados à educação básica pública com o Fundeb, promoveram diferenças de atendimento nas redes estadual e municipal de ensino em Roraima, pois é evidente a participação expressiva da rede estadual na oferta dos anos finais do ensino fundamental e médio, em contrapartida a rede municipal oferta majoritariamente a educação infantil e os anos iniciais do ensino fundamental.

Provavelmente esse fato pode não ser uma situação isolada de Roraima, mas uma tendência nacional a partir da implementação do Fundeb, em que os estados ofertam cada vez mais matrículas nos anos finais do ensino fundamental e médio e os municípios na educação infantil e anos iniciais do ensino fundamental, contudo, devem ser desenvolvidos novos estudos, que possam evidenciar tais elementos e ainda incorporem outras demandas tais como o Gasto-Aluno, CAQi, entre outros.

\section{Referências}

ARELARO, L.R.G. A não transparência nas relações público-privadas: o caso das creches conveniadas. In: ADRIAO, T.; PERONI, V. (Org.). Público e privado na educação: novos elementos para o debate. São Paulo: Xamã, 2008. p. 51-66.

BASSI, Marcos Edgar. FERMINO, Phelipe Pires. O Atendimento à Educação Básica em Santa Catarina: repercussões do FUNDEF e do FUNDEB na matrícula pública. 2011. Disponível em: https://www.researchgate.net/publication/307750650_POLITICA_DE_FUNDOS_E_EDUCA CAO_BASICA_EM_SANTA_CATARINA. Acesso em: 01 de ago. 2020.

BRASIL. Constituição da República Federativa do Brasil. Brasília, DF, 5 out. 1988. 
BRASIL. Lei $n^{\circ}$ 9.394, de 20 de dezembro de 1996. Estabelece diretrizes e bases da educação nacional. Diário Oficial da União, Brasília, DF, 23 dez. 1996.

BRASIL. Emenda Constitucional $\mathbf{n}^{\circ}$ 53, de 19 de dezembro de 2006. Dá nova redação aos art. $7^{\circ}, 23,30,206,208,211$ e 212 da Constituição Federal e ao art. 60 do Ato das Disposições Constitucionais Transitórias.

BRASIL. Lei n ${ }^{\circ}$ 1 1.494, de 20 de junho de 2007. Regulamenta o Fundo de Manutenção e Desenvolvimento da Educação Básica e de Valorização dos Profissionais da Educação FUNDEB. Diário Oficial da União, Brasília, DF, 21 jun. 2007.

BRASIL. Emenda Constitucional n 59, de 19 de dezembro de 2009. Dá nova redação aos art. $7^{\circ}, 23,30,206,208,211$ e 212 da Constituição Federal e ao art. 60 do Ato das Disposições Constitucionais Transitórias.

BRASIL. Emenda Constitucional $\mathrm{n}^{\circ}$ 14, de 12 de setembro de 1996. Modifica os arts. 34, 208, 211 e 212 da Constituição Federal e dá nova redação ao art. 60 do Ato das Disposições Constitucionais Transitórias. Diário Oficial da União, Brasília, 1996.

BRASIL. Plano Nacional de Educação, Lei 13.005/2014. Aprova o Plano Nacional de Educação PNE e dá outras providências. Diário Oficial da União, Brasília, DF, 26 jun. 2014.

BRASIL. Fundo Nacional de Desenvolvimento da Educação. Sobre FUNDEB. Brasília, DF: FNDE, 2007. Disponível em: https://www.fnde.gov.br/financiamento/fundeb/sobre-Oplano-ou-programa/sobre-o-fundeb. Acesso em: 06/02/2021.

BRASIL. Portaria Interministerial n. 03, de 13 de dezembro de 2019. Ministério da Educação. Reajusta os parâmetros operacionais do Fundo de Manutenção e Desenvolvimento da Educação Básica e de Valorização dos Profissionais da Educação Fundeb para o exercício de 2019. Brasília, DF, dezembro, 2019. Disponível em: https://www.in.gov.br/en/web/dou/-/portaria-interministerial-n-3-de-13-de-dezembrode-2019-234965744. Acesso em: 06/02/2021.

BRASIL. Senado Federal. Regulamentação do Fundeb é um dos itens da pauta do Senado nesta terça. Agência Senado, Jornal do Senado. Brasília: Senado Federal, 2020.

GOMES, Debora Aparecida Pereira. As consequências do FUNDEB para a oferta da educação básica em dois municípios da Região Metropolitana de Campinas: análise das alterações na divisão de responsabilidades entre os entes federados (2005-2012). Dissertação (Mestrado em Educação), Universidade Estadual de Campinas, Campinas-SP, 2014. Disponível em:

http://repositorio.unicamp.br/bitstream/REPOSIP/254132/1/Gomes_DeboraAparecidaPereira _M.pdf. Acesso em: 01 de ago. 2020.

KRIPKA, Rosana Maria Luvezute; SCHELLER, Morgana; BONOTTO, Danusa de Lara. Pesquisa documental na pesquisa qualitativa: conceitos e caracterização. Revista de investigaciones UNAD, Bogotá, n. 14, julio-diciembre 2015. Disponível em:

https://proceedings.ciaiq.org/index.php/ciaiq2015/article/view/252. Acesso em: 06 fev. 2021. DOI: https://doi.org/10.22490/25391887.1455. 
Revista Educação e Políticas em Debate - v. 10, n. 1, p. 361-378, jan./abr. 2021 - ISSN 2238-8346

MELCHIOR, J. C. A. Mudanças no financiamento da educação no Brasil. Campinas: Autores Associados, 1997.

LABORATÓRIO DE DADOS EDUCACIONAIS. Plataforma de Dados Educacionais: indicador de número de Matrículas. LDE, 2020. Disponível em:

https://dadoseducacionais.c3sl.ufpr.br/. Acesso em: 06/02/2021.

PINTO, José Marcelino de Rezende. A política recente de fundos para o financiamento da educação e seus efeitos no pacto federativo. Educ. Soc., Campinas, vol. 28, n. 100 - Especial, p. 877-897, out. 2007. Disponível em: https://www.scielo.br/pdf/es/v28n100/a1228100.pdf. Acesso em: 15 de set. 2020. DOI: https://doi.org/10.1590/s0101-73302007000300012.

PINTO, J.M.R.; ALVES, T. O impacto financeiro da ampliação da obrigatoriedade escolar no contexto do Fundeb. Educação \& Realidade, Porto Alegre, v.36, n.2, p.605-624, maio/ago. 2011. Disponível em: https://seer.ufrgs.br/educacaoerealidade/article/view/15128/12931. Acesso em: 15 de set. 2020.

SALES, Luis Carlos; SILVA, Magna Jovita Gomes de Sales. A movimentação das matrículas no ensino fundamental no Estado do Piauí. Educação \& Realidade, Porto Alegre, v. 38, n. 4, p. 1283-1301, out./dez. 2013. Disponível em:

https://www.scielo.br/pdf/edreal/v38n4/15.pdf. Acesso em: 22 de set. 2020. DOI:

https://doi.org/10.1590/s2175-62362013000400015.

SANTOS, Joedson Brito dos; SOUZA JUNIOR, Luiz de. Educação Infantil: 20 anos da primeira etapa da educação básica e dos desafios do financiamento. Revista Contemporânea de Educação, vol. 12, n. 24, mai/ago de 2017. Disponível em:

https://revistas.ufrj.br/index.php/rce/article/view/3685. Acesso em: 22 de set. 2020. DOI: https://doi.org/10.20500/rce.v12i24.3685.

SONOBE, Aline Kazuko; PINTO, José Marcelino de Rezende; RIBEIRO, Josete Maria Cangussú. Análise da evolução dos gastos por aluno em alguns estados brasileiros, suas respectivas capitais e sua relação com o Fundeb. RBPAE, v.34, n.2, p. 395-411, mai./ago. 2018. Disponível em: https://seer.ufrgs.br/rbpae/article/download/86366/49648. Acesso em: 22 de set. 2020. DOI: https://doi.org/10.21573/vol34n22018.86366. 
Revista Educação e Políticas em Debate - v. 10, n. 1, p. 361-378, jan./abr. 2021 - ISSN 2238-8346

\section{Apêndice A}

Tabela A - Roraima - movimentação financeira do Fundeb, segundo a contribuição e a receita do governo estadual e dos municípios - 2009 a 2019. Em R\$.

\begin{tabular}{l|l|r|r|r|r}
\hline Anos & $\begin{array}{l}\text { Total de } \\
\text { Receita }\end{array}$ & $\begin{array}{c}\text { Contribuição do } \\
\text { Estado }\end{array}$ & $\begin{array}{c}\text { Receita do } \\
\text { Estado }\end{array}$ & $\begin{array}{c}\text { Contribuição dos } \\
\text { Municípios }\end{array}$ & \multicolumn{1}{c}{$\begin{array}{c}\text { Receita dos } \\
\text { Municípios }\end{array}$} \\
\hline 2009 & 357.695 .060 & 278.460 .803 & 242.230 .984 & 78.495 .750 & 115.464 .077 \\
2010 & 371.060 .890 & 306.274 .485 & 246.377 .075 & 61.716 .815 & 124.683 .816 \\
2011 & 424.906 .326 & 364.212 .502 & 288.776 .577 & 56.999 .173 & 136.129 .749 \\
2012 & 435.255 .320 & 379.643 .169 & 288.211 .952 & 61.243 .564 & 147.043 .368 \\
2013 & 502.732 .057 & 412.694 .616 & 318.709 .914 & 92.763 .014 & 184.022 .143 \\
2014 & 559.313 .558 & 455.505 .574 & 339.761 .012 & 109.831 .803 & 219.552 .546 \\
2015 & 584.268 .730 & 481.209 .228 & 350.194 .727 & 110.212 .396 & 234.074 .003 \\
2016 & 684.561 .691 & 551.295 .349 & 393.746 .186 & 131.739 .054 & 290.815 .504 \\
2017 & 645.681 .873 & 519.759 .164 & 358.014 .459 & 121.604 .961 & 287.667 .414 \\
2018 & 680.432 .088 & 546.570 .369 & 372.627 .470 & 144.713 .683 & 307.804 .617 \\
2019 & 767.922 .907 & 667.902 .217 & 453.689 .136 & 151.878 .589 & 314.233 .771 \\
\hline
\end{tabular}

Fonte: SIOPE/FNDE 